\title{
TINGKAT PARTISIPASI ANGGOTA KELOMPOK TANI TERNAK "PANDAN MULYO" SRANDAKAN, BANTUL
}

\author{
F.H.T Saptarini, B. Guntoro, dan E. Sulastri'
}

\section{INTISARI}

Penelitian ini bertujuan untuk mengetahui tingkat partisipasi dan menganalisis faktorfaktor sosial ekonomi yang berhubungan dengan tingkat partisipasi antar anggota kelompok di Kelompok Tani Ternak "Pandan Mulyo" Poncosari, Srandakan, Bantul. Penelitian ini merupakan studi kasus yang mengambil semua anggota kelompok sebagai responden yaitu sebanyak 137 . Penelitian dilakukan pada bulan Desember 2006 sampai Februari 2007 dengan metode wawancara dan kuesioner. Data yang diperoleh kemudian ditabulasi dan dianalisis menggunakan analisis deskriptif, korelasi Spearman, Chi-Square, dan uji Phi. Hasil penelitian menunjukkan bahwa partisipasi anggota pada tahap perencanaan dan monitoring dan evaluasi pada tingkat yang sedang, sedangkan pada tahap pelaksanaan dan sharing benefit pada tingkat yang tinggi. Uji statistik menunjukkan bahwa umur peternak $(r=0,213, P<0,01)$, pengalaman beternak $(r=0,353$; $\mathrm{P}<0,01)$, kepemilikan ternak $(\mathrm{r}=0,295 ; \mathrm{P}<0,05)$, kontribusi pendapatan $(\mathrm{r}=0,180 ; \mathrm{P}<0,05)$, sikap peternak $\left(X^{2}=114,051 ; P<0,01 ; \Phi=0,915\right)$, kedudukan dalam kelompok $\left(X^{2}=89,934 ; P<0,01 ; \Phi\right.$ $=0,809)$, dan pekerjaan pokok $\left(\mathrm{X}^{2}=25,409 ; \mathrm{P}<0,01 ; \Phi=0,430\right)$ berhubungan dengan tingkat partisipasi anggota.

(Kata kunci: Faktor-faktor sosial ekonomi, Tingkat partisipasi, Kelompok peternak sapi)

Buletin Peternakan 31 (2): 101-110, 2007

\footnotetext{
'Fakultas Peternakan Universitas Gadjah Mada, Yogyakarta.
} 


\title{
LEVEL OF PARTICIPATION OF MEMBERS IN "PANDAN MULYO" FARMER GROUP, SRANDAKAN, BANTUL
}

\begin{abstract}
This research was aimed to investigate the level of participation and to analyze the factors related to the level of participation in the cattle farmer group of "Pandan Mulyo" Poncosari Village, Srandakan, Bantul. This research was a case study which gathered all the member of farmer group as respondents. This research was done in December 2006 until February 2007 by interview and questionnaire methods. The data were tabulated and analyzed using descriptive statistics, Spearman's Rank Correlation, Chi-Square, and Phi Tests. The results showed that in the planning and monitoring and evaluation stages, the level of participation of the members were in medium level, while implementation and sharing benefits stages were in high level of participation. Statistical analyses showed that farmer's ages $(r=0.213 ; \mathrm{P}<0.01)$, experience $(r=$ $0.353 ; \mathrm{P}<0.01)$, cattle ownership in raising cattle $(\mathrm{r}=0.295 ; \mathrm{P}<0.05)$, income contribution $(\mathrm{r}=$ $0.180 ; \mathrm{P}<0.05)$, farmer's attitude $\left(\mathrm{X}^{2}=114.051 ; \mathrm{P}<0.01 ; \Phi=0.915\right)$, status in group $\left(\mathrm{X}^{2}=89.934\right.$; $\mathrm{P}<0.01 ; \Phi=0.809)$, and main occupation $\left(\mathrm{X}^{2}=25.409 ; \mathrm{P}<0.01 ; \Phi=0.430\right)$ had significant relationship with level of participation.
\end{abstract}

(Key words: Social economic factors, Level of participation, Cattle farmer group)

\section{Pendahuluan}

Keberhasilan usaha pemerintah untuk mengembangkan program pengembangan peternakan di pedesaan tentunya tidak akan lepas dari partisipasi anggota kelompok ternak. Keberadaan pemerintah di sini hanya sebagai inovator dan motivator sedangkan keberhasilan dari program dan pelaksanaannya sebagian besar ditentukan oleh anggota kelompok ternak sendiri.

Ban and Hawkins (1996) menjelaskan bahwa partisipasi yang melibatkan mayarakat dalam program pembangunan adalah salah satu cara untuk membuat program lebih berhasil, khususnya dalam memecahkan permasalahan dalam masyarakat miskin. Partisipasi adalah kontribusi secara sukarela dari anggota kelompok/masyarakat untuk sebuah proyek dapat berbentuk tenaga kerja, uang maupun bentuk lainnya (Muller-Glodde, 1991).

Tingkat partisipasi antar anggota kelompok ditentukan oleh bagaimana program pemerintah tersebut dilaksanakan oleh anggota kelompok peternak. Persepsi anggota kelompok untuk berpartisipasi terhadap suatu program tidaklah sama. Hal ini bisa disebabkan adanya sebagian anggota kelompok peternak yang tidak mau menerima program yang dibuat oleh pemerintah sehingga partisipasi anggota kelompok terhadap program tersebut rendah.

Ada empat bentuk atau tahapan dalam partisipasi menurut Uphoff et al. (1979) yaitu pengambilan keputusan atau perencanaan, pelaksanaan, berbagi manfaat, dan monitoring dan evaluasi. Pelaksanaan program yang dilakukan oleh pemerintah dan instansi lain umumnya bersifat top-down. Pelaksanaan program tersebut tidak melibatkan peternak dalam proses perencanaan dan evaluasi kegiatan program. Peternak hanya diikutsertakan pada pelaksanaan program saja sehingga program tersebut tidak berjalan optimal.

Program pengembangan ternak yang bersifat top-down menyebabkan petani peternak enggan melaksanakan program tersebut. Jika peternak enggan menerima program tersebut otomatis motivasi untuk berpartisipasi terhadap program tersebut 
rendah apalagi untuk bekerja sama dengan baik. Oleh karena itu partisipasi dan kerja sama antar anggota kelompok tani ternak mutlak diperlukan dalam usaha peningkatan produksi ternak.

Partisipasi masyarakat terhadap pembangunan peternakan di daerah sangat penting. Untuk itu perlu dilakukan penelitian tentang hal itu. Penelitian telah dilaksanakan di Kelompok Tani Ternak "Pandan Mulyo" Poncosari, Srandakan, Bantul, Yogyakarta. Peneliti memilih lokasi tersebut karena selama ini tingkat partisipasi antar anggota kelompok terhadap program-program yang dilaksanakan pemerintah belum dapat diketahui dengan jelas.

Untuk itu, penelitian ini diharapkan dapat menjawab pertanyaan-pertanyaan penelitian sebagai berikut: Bagaimana tingkat partisipasi antar anggota Kelompok Tani Ternak "Pandan Mulyo" dalam melaksanakan kegiatan peternakannya? dan faktor-faktor sosial ekonomi apa saja yang berhubungan dengan tingkat partisipasi anggota Kelompok Tani Ternak "Pandan Mulyo"?.

Penelitian ini bertujuan untuk: 1) Mengetahui tingkat partisipasi anggota kelompok dan 2) Menganalisis faktor-faktor sosial ekonomi yang berhubungan dengan tingkat partisipasi antar anggota kelompok.

\section{Materi dan Metode}

Materi yang digunakan untuk mendapatkan data dalam penelitian ini adalah kuesioner. Responden yang digunakan adalah seluruh anggota Kelompok Tani Ternak "Pandan Mulyo" di Dusun Ngentak, Poncosari, Srandakan, Bantul, Yogyakarta yang berjumlah 137 orang.

Metode yang digunakan dalam pengambilan data primer adalah dengan menggunakan wawancara dan kuesioner. Rancangan yang digunakan adalah rancangan studi kasus. Sebelum dilaksanakan penelitian, kuesioner diuji validitas dan reabilitasnya di Kelompok Tani Ternak "Anggayuh Rahayu" Dusun Kaligondang, Sumbermulyo,
Bambanglipuro, Bantul yang anggotanya sebanyak 26 orang.

Analisis data yang digunakan adalah analisis deskriptif yaitu: rata-rata, standar deviasi dan persentase (\%). Untuk menganalisis hubungan antara faktor-faktor sosial ekonomi dengan tingkat partisipasi antar anggota kelompok digunakan analisis Spearman's Correlation, Chi-Square dan uji Phi.

Batasan Operasional partisipasi adalah keterlibatan diri anggota kelompok pada suatu tekad yang telah menjadi kesepakatan bersama, mempunyai tujuan tertentu dan dilakukan bersama-sama untuk mencapai suatu tujuan yang diharapkan oleh semua anggota kelompok ternak yang meliputi: kerja bakti membersihkan lokasi kandang, ronda malam/giliran menjaga kandang di malam hari, gotong royong dalam pembangunan balai pertemuan dan mushola, partisipasi untuk menghadiri pertemuan kelompok setiap hari Rabu Kliwon. Batasan operasional pada partisipasi ini adalah partisipasi anggota kelompok pada program Kredit Bogasari, Proyek Peternakan Tahun Anggaran 2002 di Pedesaan (PPAP) dan Proyek Kawasan Sentra Produksi (PKSP).

Tahap-tahap partisipasi meliputi: perencanaan (planning), pelaksanaan kegiatan, monitoring dan evaluasi, serta sharing benefits (berbagi manfaat). Masingmasing tahap dinyatakan dalam pernyataan. Masing-masing pernyataan digunakan Skala Likert yang diberi skor 5, 4, 3, 2, 1 secara berturut-turut. Skor 5 untuk pernyataan ST (Sangat Tinggi), skor 4 untuk pernyataan $T$ (Tinggi), skor 3 untuk pernyataan S (Sedang), skor 2 untuk pernyataan R (Rendah), skor 1 untuk pernyataan SR (Sangat Rendah).

Beberapa pernyataan sebagai indikator dalam perencanaan adalah: 1) Saya ikut menentukan jadwal pertemuan rutin kelompok; 2) Saya berperan serta memberikan usulan tentang pelaksanaan kegiatan kelompok yang akan dilaksanakan; 3) Saya ikut memberikan usulan dalam kegiatan pembuatan kandang; 4) Saya turut serta 
menentukan berapa jumlah sapi yang akan dipelihara di kandang kelompok; 5) Saya ikut serta memberikan usulan dalam menentukan bahan pakan yang akan diberikan pada ternak selama pemeliharaan di kandang kelompok; 6) Saya ikut serta menentukan sistem pemberian pakan pada ternak; 7) Setiap anggota kelompok membuat perencanaan setiap periode tertentu; dan 8) Saya ikut merencanakan berbagai kegiatan kelompok seperti ronda malam, gotong royong, dll.

Pernyataan dalam tahap pelaksanaan adalah: 1) Saya selalu hadir pada pertemuan rutin kelompok; 2) Saya sering terlibat dalam kegiatan-kegiatan kelompok seperti ronda malam, gotong royong, arisan, kerja bakti membersihkan kandang; 3) Saya selalu melaksanakan kegiatan sesuai dengan jadwal yang sudah ditentukan; 4) Saya bertanggung jawab secara penuh terhadap semua kegiatan kelompok; 5) Saya selalu melaksanakan kegiatan yang sudah direncanakan oleh anggota kelompok; 6) Saya tidak akan melaksanakan kegiatan kelompok yang tidak sesuai dengan hati nurani saya; 7) Saya tidak akan melaksanakan kegiatan kelompok yang bukan berasal dari usulan saya; dan 8) Semua pelaksanaan kegiatan kelompok merupakan tanggung jawab dari semua anggota.

Pernyataan dalam tahap monitoring dan evaluasi adalah: 1) PPL (pihak dinas) selalu hadir pada setiap pertemuan rutin kelompok; 2) Keberadaan PPL dalam rapat dapat menambah motivasi bekerja agar lebih giat; 3) PPL selalu mengevaluasi kegiatan kelompok setiap pertemuan rutin; 4) Semua kegiatan kelompok selalu dimonitoring/dipantau oleh PPL; 5) Setiap pertemuan kelompok, PPL selalu memberikan materi penyuluhan; 6) Materi penyuluhan yang diberikan oleh PPL adalah permasalahan yang sedang dihadapi oleh kelompok beserta cara pemecahan masalahnya; 7) Anggota dilibatkan ke dalam monitoring pada pelaksanaan kegiatan kelompok; 8) Pemerintah/PPL selalu ikut campur tangan dalam monitoring dan evaluasi kegiatan kelompok; dan 9) Monitoring dan evaluasi keuangan dilakukan sepenuhnya oleh anggota kelompok.

Pernyataan dalam tahap berbagi manfaat adalah: 1) Saya merasa aman dengan adanya kegiatan ronda malam di kandang kelompok; 2) Saya merasa lebih dapat mempererat hubungan silaturahmi dengan warga masyarakat setempat; 3) Saya merasa beruntung dapat memanfaatkan lahan kosong di pesisir pantai tanpa harus membayar uang sewa; 4) Dengan adanya kandang kelompok, maka dapat menambah pendapatan keluarga saya; 5) Dengan mengikuti kegiatan kelompok, saya turut berperan serta dalam menambah kas kelompok; 6) Saya tidak mendapatkan keuntungan apa-apa dari hasil kegiatan kelompok; dan 7) Saya mendapatkan keuntungan dari pengumpulan pupuk kandang secara kolektif oleh anggota kelompok.

\section{Hasil dan Pembahasan}

\section{Keadaan umum wilayah}

Kelompok Tani Ternak "Pandan Mulyo" terletak di Dusun Ngentak, Desa Poncosari, Kecamatan Sraǹdakan, Bantul, tepatnya di pesisir Pantai Pandan Simo, bagian barat daya Kabupaten Bantul, Yogyakarta. Sebelảh utara berbatasan dengan Desa Trimurti (Kecamatan Srandakan), sebelah timur berbatasan dengan Desa Gadingsari (Kecamatan Sanden), sebelah selatan berbatasan dengan Samudra Indonesia dan sebelah barat berbatasan dengan Sungai Progo. Desa Poncosari ini terletak pada ketinggian $2 \mathrm{~m} \mathrm{dpl}$, dan bersuhu $30^{\circ} \mathrm{C}$. Curah hujan rata-rata $2.000-3.000$ $\mathrm{mm}$ /tahun dengan luas wilayah $1.186,1220$ ha.

\section{Profil kelompok tani ternak "Pandan Mulyo"}

Kelompok Tani Ternak "Pandan Mulyo" didirikan pada tanggal 11 Januari 1994. Pada awal berdiri terdiri dari 68 anggota dan jumlah anggota saat ini sebanyak 137 peternak, sedangkan jumlah sapi potong adalah 420 ekor. Tanah yang digunakan untuk kandang adalah milik Kasultanan Yogyakarta 
(Sultan's Ground/SG), tidak ada hak milik bagi peternak tetapi hanya hak pakai tanpa membayar uang sewa. Luas kandang kelompok ini sekitar 1,5 hektar.

Penyuluhan diadakan setiap hari Rabu Kliwon bersama dengan jadwal pertemuan rutin kelompok. Kegiatan penyuluhan tersebut dibantu oleh seorang Petugas Penyuluh Lapangan (PPL) dari Dinas Peternakan, Kelautan dan Perikanan (PKP) Kabupaten Bantul yang membawahi setiap 1 kecamatan. Topik yang dibahas setiap pertemuan kelompok adalah sesuai dengan situasi dan kondisi peternak saat itu.

Prestasi yang pernah diraih oleh Kelompok Tani Ternak "Pandan Mulyo" ini antara lain: juara I lomba kelompok ternak tingkat kabupaten tahun 1997, juara II lomba kelompok ternak tingkat provinsi tahun 2004 dan peringkat ke-7 lomba kelompok ternak tingkat nasional pada tanggal 3 Agustus 2005. Struktur organisasi yang ada sudah lengkap dan terorganisasi dengan baik. Kredit dari pemerintah maupun perusahaan swasta yang sudah pernah dilaksanakan antara lain: Bogasari, Proyek Peternakan Tahun Anggaran 2002 di Pedesaan (PPAP) dan Proyek Kawasan Sentra Produksi (PKSP). Pemberian kredit secara bergilir supaya terjadi pemerataan antar anggota kelompok. Jenis sapi potong yang ada antara lain: Peranakan Ongole (PO), Limousine dan Simmental. Permasalahan yang sering dihadapi adalah apabila sapi birahi jika dikawinkan dengan inseminasi buatan sulit jadi karena ada keterlambatan inseminator atau mantri hewan yang datang, selain itu juga karena keterlambatan peternak untuk mendeteksi birahi.

\section{Tingkat partisipasi antar anggota} Kelompok terhadap program Pemerintah

Tahap-tahap partisipasi meliputi: perencanaan, pelaksanaan, monitoring dan evaluasi serta sharing benefits (berbagi manfaat) kepada sesama anggota kelompok. Setiap tahap mempunyai skor masing-masing.
Perencanaan. Perencanaan merupakan salah satu faktor penting dalam melakukan suatu kegiatan. Tanpa adanya perencanaan yang baik maka kegiatan tidak akan terlaksana dengan baik. Perencanaan ini merupakan tahap awal pada proses partisipasi anggota dalam suatu kelompok. Keterlibatan anggota dalam perencanaan program sangat menentukan keberhasilan program kerja yang akan dilaksanakan dalam kelompok. Keikutsertaan anggota dalam melaksanakan program yang akan dilaksanakan akan mempengaruhi tingkat partisipasi anggota terhadap kelompok tani ternak tersebut.

Tabel 1 menjelaskan bahwa mayoritas responden mempunyai partisipasi sedang pada tahap perencanaan $(62,77 \%)$, sedangkan $24,09 \%$ responden pada tingkat partisipasi perencanaan yang tinggi dan hanya $13,14 \%$ responden dalam tingkat partisipasi yang rendah dalam perencanaan. Keterlibatan peternak di setiap tahap partisipasi merupakan hak bagi setiap anggota kelompok. Sebaiknya semua anggota dilibatkan dalam setiap tahap partisipasi dan harus aktif dalam kegiatan kelompok tersebut. Untuk meningkatkan tingkat partisipasi maka sebaiknya semua anggota ikut terlibat dalam proses perencanaan kegiatan di kandang kelompok.

Pelaksanaan. Tahap kedua dari partisipasi adalah pelaksanaan program. Tahap ini adalah melaksanakan programprogram kelompok yang sudah direncanakan sesuai dengan tujuannya. Pelaksanaan program kerja yang baik akan meningkatkan tingkat partisipasi terhadap kegiatan kelompok. Keberhasilan suatu program sangat ditentukan pada tahap pelaksanaan ini. Pelaksanaan program yang baik akan memberikan manfaat yang baik pula pada anggotanya.

Hasil penelitian menyatakan bahwa $67,88 \%$ responden mempunyai tingkat partisipasi pada tahap pelaksanaan program tinggi, 31,39\% menyatakan pada tingkat yang sedang dan $0,73 \%$ pada tingkat partisipasi yang rendah dalam pelaksanaan (Tabel 2). 
Monitoring dan evaluasi. Penyuluhan pertanian selain memberikan pengetahuan Tentang pertanian dan peternakan juga harus merangsang petani peternak agar timbul kesadaran untuk melaksanakan kerja nyata, mempraktekkan sendiri pengetahuan yang sudah diterimanya. Monitoring adalah proses pengumpulan informasi dan pemantauan secara terusmenerus proses perencanaan dan pelaksanaan program. Monitoring dapat dilakukan secara langsung atau membaca hasil laporan pelaksanaan program (Marjuki dan Suharto, 1996 dalam Suharto, 2005). Hasil penelitian menunjukkan bahwa $53,28 \%$ responden memiliki tingkat partisipasi yang sedang dalam monitoring dan evaluasi, 43,07\% lainnya memiliki tingkat yang tinggi, sedangkan sisanya $3,65 \%$ memiliki tingkat partisipasi yabng rendah (Tabel 3). Sharing benefits. Sharing benefits atau berbagi manfaat ini berkaitan dengan hak bagi setiap anggota kelompok. Dari hasil analisis statistik (Tabel 4) diperoleh data bahwa sebagian besar responden $(76,64 \%)$ menyatakan merasakan memiliki tingkat partisipasi tinggi pada tahap sharing benefits, sedangkan sisanya $23,36 \%$ menyatakan memiliki partisipasi yang sedang. Hal ini menunjukkan bahwa semua aktivitas yang dilakukan oleh peternak dan kelompoknya pada akhirnya akan memberikan manfaat kepada para anggotanya.

Tabel 1. Tingkat partisipasi tahap perencanaan anggota kelompok tani ternak di "Pandan Mulyo" (Level of participation in planning stage of members in "Pandan Mulyo")

\begin{tabular}{lcc}
\hline $\begin{array}{c}\text { Tingkat Partisipasi (Level } \\
\text { Of Participation) }\end{array}$ & $\begin{array}{c}\text { Jumlah Responden (Orang) (Number of } \\
\text { Respondents (Person) }\end{array}$ & $\begin{array}{c}\text { Persentase } \\
\text { (Percentage) }(\%)\end{array}$ \\
\hline Rendah (low) & 18 & 13,14 \\
Sedang (medium) & 86 & 62,77 \\
Tinggi (high) & 33 & 24,09 \\
\hline \multicolumn{1}{c}{ Total } & 137 & 100,00 \\
\hline
\end{tabular}

Tabel 2. Tingkat partisipasi (pelaksanaan) anggota kelompok tani ternak "Pandan Mulyo" (Level of participation in implementation stage of members in "Pandan Mulyo")

\begin{tabular}{lcc}
\hline \hline $\begin{array}{c}\text { Tingkat Partisipasi (Level of } \\
\text { Participation) }\end{array}$ & $\begin{array}{c}\text { Jumlah Responden (Orang) } \\
\text { (Number of Respondents (Person) }\end{array}$ & Persentase(Percentage)(\%) \\
\hline Rendah (low) & 1 & 0,73 \\
Sedang (medium) & 43 & 31,39 \\
Tinggi (high) & 93 & 67,88 \\
\hline \multicolumn{1}{c}{ Total } & 137 & 100 \\
\hline
\end{tabular}

Tabel 3. Tingkat partisipasi dalam tahap monitoring dan evaluasi anggota kelompok tani ternak "Pandan Mulyo" (Level of participation in monitoring and evaluation stage of members in "Pandan Mulyo")

\begin{tabular}{lcc}
\hline \hline $\begin{array}{c}\text { Tingkat Partisipasi (Level of } \\
\text { Participation) }\end{array}$ & $\begin{array}{c}\text { Jumlah Responden (Orang)/ } \\
\text { Number of Respondents (Person) }\end{array}$ & $\begin{array}{c}\text { Persentase (Percentage) } \\
(\%)\end{array}$ \\
\hline Rendah (low) & 5 & 3,65 \\
Sedang (medium) & 73 & 53,28 \\
Tinggi (high) & 59 & 43,07 \\
\hline \multicolumn{1}{c}{ Total } & 137 & 100 \\
\hline
\end{tabular}


Hubungan karakteristik peternak terhadap tingkat partisipasi dalam kelompok tani ternak

Dari hasil olah data menggunakan Korelasi Spearman dinyatakan bahwa tidak semua variabel mempunyai hubungan yang signifikan terhadap tingkat partisipasi (Tabel 5). Angka Korelasi Spearman berkisar antara 0 (tidak ada korelasi sama sekali) sampai dengan 1 (korelasi sempurna). Sebagai pedoman sederhana, koefisien korelasi lebih besar 0,5 menunjukkan korelasi cukup kuat, sedangkan kurang dari 0,5 korelasi lemah. Selain itu tanda korelasi juga berpengaruh terhadap penafsiran hasil. Tanda negatif (-) menunjukkan adanya hubungan yang berlawanan, sedangkan tanda positif $(+)$ menunjukkan hubungan yang sama (Santoso, 2003).

Hasil analisis statistik menunjukkan bahwa variabel-variabel yang signifikan antara lain: umur peternak, pengalaman beternak, kepemilikan ternak dan kontribusi pendapatan (Tabel 5).

Umur peternak. Koefisien korelasi antara variabel umur dan tingkat partisipasi sebesar 0,213 ( $\mathrm{P}<0,05)$, hal ini menunjukkan bahwa ada korelasi positif antara umur dan tingkat partisipasi. Responden yang mempunyai umur pada kisaran usia 10-64 tahun cenderung memiliki partisipasi yang tinggi. Hal ini disebabkan bahwa semakin meningkatnya umur peternak (pada usia produktif) maka inovasi teknologi yang diajarkan mudah diserap dan dilaksanakan sehingga akan meningkatkan partisipasi terhadap kelompoknya. Semakin banyak umur juga belum tentu partisipasinya akan meningkat, tingkat partisipasi peternak di atas batas usia produktif biasanya menurun karena seiring dengan tingkat kondisi kesehatan dan kekuatan bekerja. Puncak produktifitas tingkat partisipasi berada pada range usia produktif.

Pengalaman beternak. Koefisien korelasi antara pengalaman beternak dengan tingkat partisipasi menunjukkan adanya hubungan positif yaitu sebesar 0,353 $(\mathrm{P}<0,01)$. Semakin lama pengalaman beternaknya, responden mempunyai kecenderungan semakin tinggi tingkat partisipasinya. Hal ini terjadi disebabkan bahwa peternak yang pengalaman beternaknya lama maka kesadaran untuk mengikuti dan melaksanakan kegiatan kelompok tinggi sehingga tingkat partisipasinya cenderung tinggi.

Kepemilikan ternak. Antara kepemilikan ternak dengan tingkat partisipasi menunjukkan korelasi positif yang mempunyai koefisien korelasi sebesar 0,295 $(\mathrm{P}<0,01)$. Hal ini menunjukkan bahwa semakin banyak jumlah ternak yang dimiliki anggota Kelompok Tani Ternak "Pandan Mulyo" maka mempunyai kecenderungan semakin tinggi partisipasi terhadap kelompoknya. Hal ini disebabkan jika semakin banyak ternak yang dimiliki dan dipelihara di kandang kelompok maka peternak akan semakin giat mengikuti kegiatan kandang kelompok.

Kontribusi pendapatan. Sama halnya dengan pendapatan peternak, antara variabel kontribusi pendapatan dengan tingkat partisipasi mempunyai hubungan positif. Koefisien korelasi antara kedua variabel tersebut $0,180(\mathrm{P}<0,05)$. Hal tersebut berarti semakin tinggi kontribusi pendapatan peternak, mempunyai kecenderungan tingkat partisipasi yang tinggi terhadap kegiatan kelompoknya. Hal tersebut disebabkan jika kontribusi pendapatan naik maka keikutsertaan dalam keanggotaan di kelompok dinilai berhasil maka tingkat partisipasinya cenderung tinggi.

Variabel-variabel yang tidak signifikan antara lain: motivasi, persepsi terhadap pendampingan, jumlah tenaga kerja, alokasi waktu, tingkat pendidikan, pendapatan peternak dan partisipasi. Hal ini membuktikan bahwa antara variabel-variabel tersebut tidak ada hubungannya (korelasinya) dengan tingkat partisipasi antar anggota Kelompok Tani Ternak "Pandan Mulyo".

Dari uji Chi-Square dan uji $P h i$, variabel sikap peternak, kedudukan dalam kelompok dan pekerjaan pokok memiliki ketergantungan/hubungan dengan tingkat 
partisipasi $(\mathrm{P}<0,01)$. Hasil uji Chi-Square dan uji $P$ hi dapat dilihat pada Tabel 6 dan tingkat kekuatan hubungan antara dua variabel dapat dilihat pada tabel 7 .

Sikap peternak. Variabel ini menunjukkan pernyataan menyenangkan dan tidak menyenangkan. Uji Chi-Square $\left(\mathrm{X}^{2}\right)$ menunjukkan adanya hubungan yang signifikan $\left(\mathrm{X}^{2}: 114,051\right.$ pada $\left.\mathrm{P}<0,01\right)$ antara variabel sikap dengan tingkat partisipasi sedangkan koefisien Phi sebesar 0,913. Koefisien $P h i$ menunjukkan tingkat kekuatan hubungan antara dua variabel. Antara sikap peternak dengan tingkat partisipasi terdapat kekuatan hubungan yang sangat kuat.

Kedudukan dalam kelompok. Kedudukan seseorang di dalam keanggotaan kelompok dinyatakan dengan pengurus dan anggota. Koefisien Chi-Square antara kedudukan dalam kelompok dengan tingkat partisipasi sebesar 89,934 $(\mathrm{P}<0,01)$ dan koefisien $P h i$ sebesar 0,809. Hal ini menunjukkan bahwa ada hubungan yang signifikan antara kedua variabel tersebut. Kekuatan hubungan kedua variabel tersebut menunjukkan hubungan yang sangat kuat..

Pekerjaan pokok. Hubungan yang sedang dan signifikan ditunjukkan oleh variabel pekerjaan pokok dengan tingkat partisipasi. Hal ini dibuktikan dengan koefisien Chi-Square sebesar 25,409 pada $\mathrm{P}<0,01$ dan koefisien $P h i$ sebesar 0,430 .

Tabel 4. Tingkat Partisipasi dalam tahap berbagi manfaat anggota kelompok tani ternak "Pandan Mulyo" (Level of participation in sharing benefits of members in "Pandan Mulyo")

\begin{tabular}{lcc}
\hline Tingkat Partisipasi & $\begin{array}{c}\text { Jumlah Responden (Orang) } \\
\text { (Level of Participation) }\end{array}$ & $\begin{array}{c}\text { Persentase } \\
\text { (Number of Respondents (Person) }\end{array}$ \\
\hline Rendah (low) & 0 & 0 \\
Sedang (medium) & 32 & 23,36 \\
Tinggi (high) & 105 & 76,64 \\
\hline \multicolumn{1}{c}{ Total } & 137 & 100 \\
\hline
\end{tabular}

Tabel 5. Hasil uji Spearman's Correlation antara tingkat partisipasi dengan variabel-variabel yang diduga memiliki hubungan (Spearman's Correlation Test of relationship between level of participation and predicted vatriables)

\begin{tabular}{lcc}
\hline \multicolumn{1}{c}{ Variabel (Variabels) } & $\begin{array}{c}\text { Probabilitas } \\
(\text { Probability) }\end{array}$ & $\begin{array}{c}\text { Spearman's Correlation } \\
\text { Coefficient }(R)\end{array}$ \\
\hline Umur peternak (farmer's age) & 0,013 & $0,213^{*}$ \\
Pengalaman beternak (experience in raising of cattle) & 0,000 & $0,353^{* *}$ \\
Kepemilikan ternak (cattle ownership) & 0,000 & $0,295^{* *}$ \\
Motivasi (motivation) & 0,659 & $-0,038$ \\
Persepsi terhadap pendampingan (perception & 0,070 & 0,155 \\
toward advisory) & & \\
Jumlah tenaga kerja (number of labors) & 0,543 & 0,052 \\
Alokasi waktu (times distribution) & 0,194 & 0,112 \\
Tingkat pendidikan (educational attainment) & 0,585 & $-0,047$ \\
Pendapatan peternak (farmer's income) & 0,908 & $-0,010$ \\
Kontribusi pendapatan (income contribution) & 0,035 & $0,180^{*}$ \\
\hline
\end{tabular}

Keterangan (remarks):

* Signifikan pada (significant at level) $\alpha=5 \%(\mathrm{P}<0,05)$.

** Signifikan pada (significant at level) $\alpha=1 \%(\mathrm{P}<0,01)$. 
Tabel 6. Hasil Uji Chi-Square dan Phi antara tingkat partisipasi dengan sikap peternak, kedudukan dalam kelompok dan pekerjaan pokok (Chi-Square and Phi tests of level of participation and farmer's attitude, status in the group and main occupation)

\begin{tabular}{lccc}
\hline \multicolumn{1}{c}{ Variabel (Variables) } & Probability & $\begin{array}{c}\text { Chi-Square } \\
\text { Coefficient }\left(\mathrm{X}^{2}\right)\end{array}$ & $\begin{array}{c}\text { Phi Coefficient } \\
(\Phi)\end{array}$ \\
\hline $\begin{array}{l}\text { Sikap peternak (farmer's attitude) } \\
\begin{array}{l}\text { Kedudukan dalam kelompok (status in } \\
\text { the group) }\end{array}\end{array}$ & 0,000 & $114,051^{*}$ & 0,913 \\
$\begin{array}{l}\text { Pekerjaan pokok (main occupation) } \\
\text { (man }\end{array}$ & 0,000 & $89,934^{*}$ & 0,809 \\
\hline
\end{tabular}

Keterangan (Remark):

*Signifikan pada (significant at level) $\alpha=1 \%(\mathrm{P}<0,01)$.

Tabel 7. Tingkat kekuatan hubungan antara dua variabel (Strength level of relationship between two variables)

\begin{tabular}{lc}
\hline \multicolumn{2}{c}{$\begin{array}{c}\text { Tingkat Kekuatan Hubungan (Strength Level of } \\
\text { Relationship) }\end{array}$} \\
\hline Sangat kuat (very strong) & $>0,70$ \\
Kuat (strong) & 0,50 \\
Sedang (medium) & 0,30 \\
Lemah (low) & 0,10 \\
\hline Sefficient $(\Phi)$
\end{tabular}

Sumber (Source): Cohen (1988) cit. Guntoro (2005).

\section{Kesimpulan}

Tingkat partisipasi anggota Kelompok Tani Ternak "Pandan Mulyo" pada tahap perencanaan adalah pada tingkatan yang sedang, namun pada tahap pelaksanaan, tahap monitoring dan evaluasi tinggi, serta pada tahap sharing benefits adalah tinggi. Secara keseluruhan dapat dikatakan bahwa tingkat partisipasi anggota Kelompok Tani Ternak "Pandan Mulyo" tinggi.

Faktor-faktor sosial ekonomi yang mempunyai hubungan yang signifikan terhadap tingkat partisipasi adalah umur peternak, pengalaman beternak, kepemilikan ternak, kontribusi pendapatan, sikap peternak terhadap program, kedudukan dalam kelompok dan pekerjaan pokok peternak. Untuk lebih meningkatkan tingkat partisipasi antar anggota maka pihak pemerintah (Dinas Peternakan) sebaiknya memprioritaskan faktor-faktor sosial ekonomi tersebut dalam pelaksanaan program-program pengembangan ternak di pedesaan yang akan dilakukan supaya memperoleh hasil yang maksimal.

\section{Daftar Pustaka}

Ban, A.W. van den, and H.S. Hawkins. 1996. Agricultural Extension. 2nd ed., Blackwell, Oxford.

Guntoro, B. 2005. Participation of Local Community in Sustainable Tourism Development in Ban Ruammit, Chiang Rai Province, Thailand. Thesis. Graduate School, Kasetsart University, Bangkok.

Santoso, S. 2003. Mengatasi Berbagai Masalah Statistik dengan SPSS versi 11.5. Elex Media Computindo, Jakarta.

Suharto, E. 2005. Membangun Masyarakat Memberdayakan Rakyat. Refika Aditama, Bandung. 
Muller-Glodde, U. 1991. Where There Is No Participation: Insights, Strategies, Case Study "Do and Don'ts" In Regional Development, Asia. Deutsche Gesellschaft für Technische Zusammenarbeit (GTZ) $\mathrm{GmbH}$,
Eschborn.

Uphoff, N.T., M. Cohen and A.A. Goldsmith. 1979. Rural Development Participation and Evaluation. Cornell University, New York. 